\title{
Genç Yetişkin Erkeklerde Sporun ve Farklı Spor Dallarının Postür ve Denge Üzerine Etkisi: Duyusal Yeniden Ağırlıklandırma ve Spor İlişsisi*
}

\author{
Hediye KANTEKİN ${ }^{1 D}$, Serkan ÖZGÜR ${ }^{2}$ iD Tuncay VAROL $^{2}$ \\ ${ }^{1}$ Gençlik Spor İl Müdürlüğü, Canik, Samsun. \\ ${ }^{2}$ Manisa Celal Bayar Üniversitesi, Tıp Fakültesi.
}

Orijinal Makale

Gönderi Tarihi: 23.03.2021
DOI:10.25307/jssr.901186

Online Yayın Tarihi: 30.06 .2021

\section{$\ddot{O} z$}

Duyusal girdi postürel kontrolde önemli rol oynar. Farklı spor dallarından sporcular postural kontrol için duyuları değişik derecelerde yeniden ağırlıklandırabilirler. Bu çalışma genç yetişkin erkeklerde postürel kontrolün sağlanmasında görme duyusunun önemini ve futbol ile basketbol eğitiminin postürel kontrolü sağlama bakımından görme duyusuna bağımlılı̆̆ ne derecede etkilediğini ortaya koyma amacıyla planlanmıştır. Lise öğrencilerinden futbol eğitimi alanlar ( $\mathrm{n}=17,17.29 \pm 0.85$ yaş), basketbol eğitimi alanlar $(n=19,16.74 \pm 0.87$ yaş) ve kontrol grubu olarak sanat eğitimi alanlar $(n=26,16.08 \pm 0.93$ yaş) çalışma evrenini oluşturmuşlardır. Pedobarografi cihazı ile statik denge değerlendirmesi için katılımcılara iki ayak üzerinde ve kararlı zeminde gözler açık ve gözler kapalı durumda ölçüm yapılmışır. Salınım alanı, salınım mesafesi ve salınım hızı (varyans) parametreleri elde edilmiştir. Göz açık ve göz kapalı ölçümler arasında grup faktörüne göre salınım mesafesi parametresinde anlamlı fark saptanırken ( $\mathrm{p}=0.031)$, salınım hızının sadece ön-arka bileşeninde anlamlı fark saptanmıştır ( $\mathrm{p}=0.017)$. Göz açık ölçümlerde gruplar arasında fark saptanmamıştır. Göz kapalı durumda futbolcular kontrol grubuna göre salınım mesafesi $(\mathrm{p}=0.008)$ ve salınım hızı bakımından anlamlı derecede daha üstün bulunmuşlardır $(\mathrm{p}=0.018)$. Futbol eğitimi alan genç yetişkin erkeklerin, görme duyusu engellendiğinde daha iyi statik denge performansına sahip oldukları gözlenmiştir. Futbol eğitimi alan grubun görme duyusu engellendiğinde postürel kontrolün sağlanmasında rol oynayan diğer duyusal girdileri (özellikle proprioseptif duyuyu) daha iyi yeniden ağırlıklandırabildiği söylenebilir.

Anahtar kelimeler: Postürel Kontrol, Görme, Spor Eğitimi, Duyusal Yeniden Ağırlıklandırma.

\section{The Effect of Sport and Different Sports Branches on Posture and Balance in Young Adult Men: Sensory Re-weighting and Sport Relations}

\begin{abstract}
Sensory input plays an important role in postural control. Athletes from different sports can re-weight the senses to varying degrees for postural control. This study was planned to determine the importance of the sense of vision in achieving postural control in young adult males and to reveal the extent to which football and basketball training affect the dependence on vision in terms of providing postural control. The high school students were divided into three groups: football group ( $\mathrm{n}=17$, $17.29 \pm 0.85$ years $)$ and basketball group $(n=19,16.74 \pm 0.87$ years $)$ and control group of non-athletes $(n=26,16.08 \pm 0.93$ years $)$. Static balance measurement was performed with a pedobarography device with eyes open and eyes closed on a stable surface. Area, distance and velocity (variance) parameters were obtained. While there was a significant difference in the sway distance parameter by the group factor between eyes open and eyes closed measurements $(p=0.031)$, a significant difference was found only in the anteroposterior component of the sway velocity $(\mathrm{p}=0.017)$. There was no difference between the groups in terms of eyes open measurements. In eyes closed state, football group showed a lower sway distance and sway velocity compared to the control group ( $\mathrm{p}=0.008$ and $\mathrm{p}=0.018$ respectively). It was observed that young adult males who received football training had better static balance performance when the vision was blocked. It can be argued that the football training group can re-weight the other sensory inputs (especially the proprioceptive sense) when vision is impaired.

Keywords: Postural Control, Vision, Sports Education, Sensory Re-weighting.
\end{abstract}

*Bu çalışma, üçüncü yazarın danışmanlığında yürütülen Hediye KANTEKİN'e ait yüksek lisans tezinden türetilmiştir.

†Sorumlu yazar: Prof. Dr. Tuncay VAROL, tuncay.varol@cbu.edu.tr, +905355660575 


\section{GíRiş}

İki ayak üzerinde sabit duruş sırasında vücuda etki eden yerçekimi kuvveti, en küçük salınım sırasında dengenin kolayca bozulmasına neden olabilecek bir momentum değişimine neden olur. Postürel kontrolün sağlanabilmesi için bu momentum değişimini düzeltebilecek karşı bir kuvvet oluşturulması ve bunun ayaklar yardımıyla destek taban alanına uygulanması gerekir. Yeterli ve uygun karşı kuvvetin oluşturulmasında hem reaktif (Horak ve Macpherson, 2010) hem de prediktif (Winter, 1995) mekanizmalar rol oynar. Vücudun kararlı bir şekilde dengede kalabilmesi için sürekli bir duyusal geribildirim gereklidir.

Postürel kararlılığın gelişiminin 16 yaşına kadar sürebileceğini gösteren çalışmalar bulunmaktadır (Cumberworth, Patel, Rogers ve Kenyon, 2007; Hirabayashi ve Iwasaki, 1995; Steindl, Kunz, Schrott-Fischer ve Scholtz, 2006). Postürel kontrol gelişiminin cinsiyet ile ilişskisi ise tartışmalıdır (Cumberworth vd., 2007; Nolan, Grigorenko ve Thorstensson, 2005). Çeşitli çalışmalarda çocukların ancak 10 yaşından sonra erişkin benzeri duyusal integrasyonu başarabildikleri öne sürülmektedir (Peterson, Christou ve Rosengren, 2006; Sparto vd., 2006).

Duyusal girdi ve geribildirim başlica görsel, vestibuler, proprioseptif ve taktil sistemler vasitasıyla sağlanır (Horak ve Macpherson, 2010). Postürel kontrolün sağlanmasında rol oynayan duyusal girdilerin her birinin ağırlığının gerektiğinde değiştirilebildiği bilinmektedir. Belirli bir durumda hangi duyusal girdi daha güvenilir ise, o duyusal girdinin postürel kontroldeki ağırlığı artmaktadır (Fetsch, Turner, DeAngelis ve Angelaki, 2009; Maurer, Mergner ve Peterka, 2005; Young vd., 1986). Bu sistemler içinde değişikliği en kolay gözlenebilen, gözlerin açılıp kapatılması yoluyla görme duyusudur (Chiba, Takakusaki, Ota, Yozu ve Haga, 2016).

Spor bilimi açısından amaçlanan, mevcut potansiyel yeteneğin, iskelet kas sistemiyle sinir sisteminin koordinasyonu içerisinde geliştirilmesidir. Sporda iyi bir performans için ve yaralanmaların önlenmesinde denge önemli bir rol üstlenir (Behm ve Anderson, 2006; Emery, Cassidy, Klassen, Rosychuk ve Rowe, 2005; Emery, Rose, McAllister ve Meeuwisse, 2007; Hellström, 2009). Denge ile sporda teknik beceri ve öğrenme hızı doğru orantılıdır ve tüm spor dalları belirli oranda denge gelişimi gerektirir (Vuillerme vd., 2001). Çocuğun gelişim süreci içinde denge ve koordinasyon eğitimi için en uygun yaş aralığının kadınlarda 11-14 yaş, erkeklerde ise 12-15 yaş olduğu bildirilmektedir (Weineck, 2004). Denge ve postürel kontrolün spor yapanlarda yapmayanlara göre, elit veya amatör sporcular arasında ve farklı spor dalları ile ilgilenen sporcular arasında farklılık gösterdiğine dair çok sayıda araştırma bulunmaktadır (Bressel, Yonker, Kras ve Heath, 2007; Gerbino, Griffin ve Zurakowski, 2007; Hrysomallis, 2011; Lamoth, van Lummel ve Beek, 2009; Paillard, 2014; Zemková, 2014). Denge egzersizleri normal bireylerde ve sporcularda postürel kontrolün gelişimini olumlu etkilemektedir (Bouteraa, Negra, Shephard ve Chelly, 2020; Emery vd., 2005; Gioftsidou vd., 2006; Zech vd., 2010).

Farklı spor dalları ile uğraşan sporcuların farklı statik denge performansına sahip olmasını açıklamaya çalışan görüşler henüz tartışmalıdır. Farklı spor dallarında yaş grubu, cinsiyet ve tecrübe seviyesi benzer olan sporcular arasındaki statik denge performans farkl1l1klarını 
açıklamaya çalışan çalı̧̧malarda, yapılan sporun özellikleri ve antrenman teknikleri öne çıkmaktadır (Bressel vd., 2007; Hrysomallis, 2011; Paillard, 2014). Bir spor dalının özelliği gereği ihtiyaç duyduğu güç, esneklik, çeviklik ve denge gibi faktörlerin ne ağırlıkta önemli olduğu ve bunların geliştirilmesi için uygulanan çalışma programlarının bu gereksinimleri ne ölçüde karşıladığı önemli görünmektedir. Bu açıdan bakıldığında belirli duyusal girdilerin antrenman yöntemleri ile geliştirilmesi yanı sıra, belirli bir duyusal girdinin güvenilir olmadığında ya da engellendiğinde, duyusal girdilerin ağırlığının değiş̧tirilebilmesinin de bu eğitimden etkilenmesi söz konusudur (Stambolieva, Diafas, Bachev, Christova ve Gatev, 2012). $\mathrm{Bu}$ durumun özellikle yapılan spor disiplinin gerektirdiği duyusal enformasyon girdisinin değişiklik göstermesinden kaynaklandığ öne sürülmüştür (Paillard ve Noé, 2006). Bu çalışmada genç yetişkin erkeklerde sporun ve farklı spor dallarının postürel kontrol ve dengenin sağlanmasında rol oynayan duyusal girdilerin yeniden ağırlıklandırılması üzerine etkisinin araştırılması amaçlanmıştır

\section{YÖNTEM}

\section{Araştırma Modeli}

Bağımlı değişkende (postürel kontrol ve denge) meydana gelen değişimi açıklamak üzere, etkisi olduğu düşünülen çok faktörlü ve çok denekli eşitlenmemiş kontrol gruplu yarı deneme modeli seçilmiştir.

\section{Çalışma Grubu}

Tüm katılımcılar 2012-2013 eğitim ve öğretim yılında Manisa Güzel Sanatlar ve Spor Lisesinde okuyan öğrencileri arasından, çalı̧̧maya katılmayı kabul eden ve çalışmaya katılmasına engel olabilecek herhangi bir sorunu olmayan erkek gönüllüler arasından seçilmişlerdir. Çalışma için ilgili resmi kurum izni ile gönüllü olan öğrenciler ve velilerinden gönüllü katılım onam formunu imzalayanlar çalı̧̧maya dahil edilmiştir. Gönüllüler alt ekstremite yaralanması, dengeyi olumsuz etkileyen nörolojik problemler (örn. vertigo), görsel problemler (örn. bir gözde görme kaybı) veya çalışmadan önceki altı ay içinde ciddi kafa travması konusunda sözel olarak sorgulanmışlar ve böyle bir durumu söz konusu olanlar çalışmadan dışlanmışlardır.

Katılımcılardan spor grubunda yer alan gönüllüler futbol (futbol grubu-FG, $\mathrm{n}=17,17.29 \pm 0.85$ yaş) ve basketbol (basketbol grubu-BG, $\mathrm{n}=19,16.74 \pm 0.87$ yaş) dallarında branş eğitimi alırken, müzik ve resim bölümü öğrencileri kontrol grubunu ( $\mathrm{KG}, \mathrm{n}=26,16.08 \pm 0.93$ yaş) oluşturdular. Katılımcıların boy ve ağıllık ölçümleri yapıldı, vücut kitle indeksleri (VKI) hesaplandı (Tablo 1). Dört senelik eğitim programında spor bölümü öğrencilerinin tümü temel spor eğitimi konuları olarak ısınma (12 saat), kuvvet (22 saat), çabukluk (18 saat), dayanıklılık (20 saat), koordinasyon (13 saat), esneklik (13 saat) ve denge (10 saat) konularında uygulamalı eğitim almaktadırlar. Temel eğitim yanı sıra kendi spor dallarına özgü koordinasyon ve teknik çalı̧̧malar yapmaktadırlar (birinci yılda 28 saat/yll, diğer yıllarda 36 saat/yıl). Kontrol grubunu oluşturan öğrencilerin sadece haftalık 2 saat beden eğitimi dersi dışında planlı fiziksel aktivitesi bulunmamaktadır. Çalışma eğitim yılı sonunda olmak üzere tüm sınıflardan öğrencilerin katılımı ile yapılmıştır. 


\section{Veri Toplama Araçları}

Boy ölçümü: Stadiometre (Charder HM200P) ile yapılmıştır.

Vücut ağırlığı ölçümü: Baskül (Tanita BC730) ile yapılmıştır.

Statik dengenin değerlendirilmesi: Statik denge ölçümleri için HR Mat (Tekscan, Boston, MA, USA) pedobarografi cihazı kullanılmıştır. Bu cihaz ile ağırlık merkezinin platform üzerindeki horizontal iz düşümünü yansıtan basınç merkezi $(\mathrm{BM})$ yer değişimi, bir başka deyişle vücut salınımı kaydedilmiştir. Her ölçüm 30 saniye süre ile ve $50 \mathrm{~Hz}$ frekansta yapılmıştır. Bu hareketin hem antero-posterior (AP) hem de medio-lateral (ML) bileşenlerinin analizi yapılmıştır. Verilerin elde edilmesinde cihazla birlikte verilen HR Mat Research Software 6.7 salınım analiz modülü kullanılmıştır. Zamana göre değişen BM pozisyonu ile salınım mesafesi (Dist), salınım hızı (Var) ve salınım alanı (Area) verileri elde edilmiştir. Bu verilerin düşük değerlerde olması daha iyi statik denge yönünde değerlendirilmektedir. Ölçümler öncesi katılımcıların fiziksel egzersiz yapmamaları ve yorgun olmamaları sağlanmıştır. Ölçüm yapılırken platform üzerindeki katılımcının ayakları topukları arasında 5 cm ve iki ayağının iç kenarları arasında 30 derecelik açı olacak şekilde konumlandırılmıştır. Katılımcılardan iki ayak üzerinde gözü açık (GA) ve iki ayak üzerinde gözü kapalı (GK) ölçümleri yapılmıştır. Gözü açık olarak alınan ölçümlerde katılımcının 2 metre uzağında ve göz hizasında bulunan, $2 \mathrm{~cm}$ çapında bir noktaya bakması sağlanarak, dikkatinin dağılmasının önüne geçilmiştir. Her ölçüm arasında katılımcıların en az 2 dakika dinlenmesi sağlanmıştır. Ölçümler sırasında normal oda 1sısı ve aydınlatması sağlanmıştır.

\section{Araştırma Etiği}

Çalışma Manisa Celal Bayar Üniversitesi Tıp Fakültesi Girişimsel Olmayan Klinik Araştırmalar Etik Kurulu tarafından onaylanmıştır (13.12.2012/298). Çalışma Helsinki Deklarasyonu Prensipleri'ne göre yapılmıştır.

\section{Verilerin Analizi}

Verilerin analizi için IBM SPSS Statistics 15.0 programı kullanılmıştır. Katılımcıların demografik verilerinin ortalama ve standart sapmaları hesaplanmıştır ve boy, ağırlık ve vücut kitle indeksi ortalama değerleri one-way ANOVA ile karşılaştırıldı. Spor eğitimi alan katılımcılar ile kontrol grubu katılımcılarının göz açık ve göz kapalı durumda statik denge parametreleri arasında fark olup olmadığını belirlemek için bağımsız örneklem t testi yapılmıştır. Bağımlı değişken olarak belirlenen statik denge parametrelerinin (Area, Dist, $\mathrm{ML}_{\text {Dist }}, \mathrm{AP}_{\text {Dist }}$, Var, MLvar, APVar) gruplara (FG, BG, KG), görme duyusuna (GA, GK) ve grupgörme etkileşimine göre değerlendirilmesi için two-way mixed ANOVA yapılmıştır. Gruplara göre görme duyusunun statik denge üzerine etkisini belirlemek için one-way ANOVA yapılmış ve gözlenen istatistiksel anlamlı farkların $(\mathrm{p}<0.05)$ post hoc analizi Bonferroni testi ile yapılmıştır. 
Kantekin, H., Özgür, S. ve Varol, T. (2021). Genç yetişkin erkeklerde sporun ve farklı spor dallarının postür ve denge üzerine etkisi: Duyusal yeniden ağırlıklandırma ve spor ilişkisi. Spor Bilimleri Araştırmaları Dergisi, 6(1), 208-219.

\section{BULGULAR}

Tablo 1. Katılımcilara ilișkin demografik bilgiler

\begin{tabular}{|c|c|c|c|c|}
\hline & FG & BG & KG & p \\
\hline & $(n=17)$ & $(n=19)$ & $(n=26)$ & \\
\hline Yaş (yıl) & $17.29 \pm 0.85$ & $16.74 \pm 0.87$ & $16.08 \pm 0.93$ & - \\
\hline Boy $(\mathbf{c m})$ & $173.32 \pm 5.59$ & $179.02 \pm 7.45$ & $173.77 \pm 6.74$ & 0.002* \\
\hline Ă̆ırlık (kg) & $67.11 \pm 6.24$ & $71.39 \pm 8.49$ & $68.22 \pm 10.56$ & 0.031* \\
\hline VKİ $\left(\mathrm{kg} / \mathrm{m}^{2}\right)$ & $22.32 \pm 1.54$ & $22.29 \pm 2.43$ & $22.63 \pm 3.45$ & 0.475 \\
\hline
\end{tabular}

Katılımcılara ait boy ve ağırlık ortalamaları arasında anlamlı farklılık saptanmıştır. Basketbol grubunun boy ortalaması ve ağırlık ortalaması hem futbol hem de kontrol grubundan anlamlı derecede daha yüksek bulundu (sirasiyla $\mathrm{p}=0.002$ ve $\mathrm{p}=0.031$ ) (Tablo 1). Vücut kitle indeksi bakımından ise gruplar arasında fark saptanmamıştır.

Tablo 2. Spor eğitimi alan gönüllüler ile kontrol grubunun göz açık ve göz kapalı durumda statik denge parametrelerinin karşılaştırılması

\begin{tabular}{clccc}
\hline & & $\begin{array}{c}\text { Spor Ĕgitimi Alanlar } \\
(\mathbf{n = 3 6})\end{array}$ & $\begin{array}{c}\text { Kontrol Grubu } \\
(\mathbf{n = 2 6})\end{array}$ & $\mathbf{p}$ \\
\hline \multirow{3}{*}{ GA } & Area & $0.798 \pm 0.49$ & $1.212 \pm 1.36$ & 0.099 \\
\cline { 2 - 5 } & Dist & $85.02 \pm 23.42$ & $94.03 \pm 30.02$ & 0.189 \\
\cline { 2 - 5 } & Var & $0.033 \pm 0.009$ & $0.036 \pm 0.012$ & 0.165 \\
\hline \multirow{3}{*}{ GK } & Area & $1.116 \pm 0.83$ & $1.30 \pm 1.137$ & 0.464 \\
\cline { 2 - 5 } & Dist & $81.62 \pm 19.61$ & $94.83 \pm 24.94$ & $\mathbf{0 . 0 2 3}$ \\
\cline { 2 - 5 } & Var & $0.031 \pm 0.007$ & $0.036 \pm 0.010$ & $\mathbf{0 . 0 3 2}$ \\
\hline
\end{tabular}

$* \mathrm{p}<0.05$

Spor eğitimi alan gruplar ile kontrol grubu arasında gözler açık durumda statik denge parametreleri arasında istatistiksel fark saptanmamışken, gözler kapalı durumda Dist ve Var parametrelerinin spor eğitimi alanlarda kontrol grubuna göre istatistiksel olarak anlamlı derecede daha iyi olduğu gözlenmiştir (sırasiyla $p=0.023$ ve $p=0.032$ ) (Tablo 2). Area parametresi bakımından hem gözler açık hem de gözler kapalı durumda yapılan ölçümler arasında anlamlı fark bulunamamıştır.

Tablo 3. Gözü açık (GA) ve gözü kapalı (GK) durumda futbol grubu (FG), basketbol grubu (BG) ve kontrol grubu $(\mathrm{KG})$ katılımcıların ortalama statik denge parametrelerinin grup faktörü, görme faktörü ve grup-görme etkileşimi bakımından karşılaştırılması

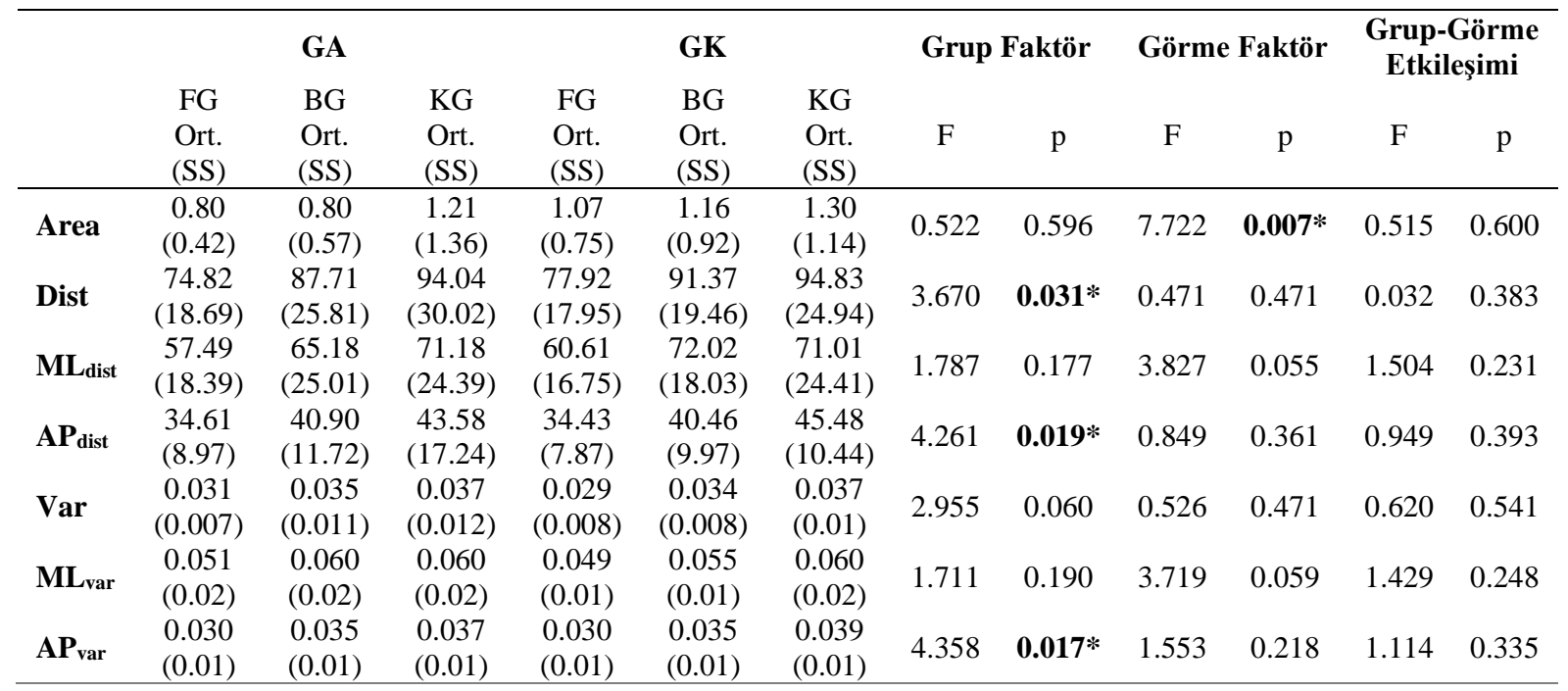


Kantekin, H., Özgür, S. ve Varol, T. (2021). Genç yetişkin erkeklerde sporun ve farklı spor dallarının postür ve denge üzerine etkisi: Duyusal yeniden ağırlıklandırma ve spor ilişkisi. Spor Bilimleri Araştırmaları Dergisi, 6(1), 208-219.

Ort. $=$ ortalama; $\mathrm{SS}=$ Standart Sapma; $\mathrm{ML}=$ medio-lateral; $\mathrm{AP}=$ antero-posterior; ${ }^{*} \mathrm{p}<0.05$

Gruplar arasında grup-görme etkileşimi bakımından hiçbir parametrede anlamlı fark saptanmamıştır (Tablo 3).

Ortalama Area parametresi üzerine grup faktörünün etkili olmadığ1 $(\mathrm{p}=0.596)$ ancak görme faktörünün gruptan bağımsız olarak farklı görme koşuluna (GA ve GK) göre istatistiksel olarak anlamlı farklılık gösterdiği saptanmıştır $\left(\mathrm{F}_{(2,59)}=0.522, \mathrm{p}=0.007\right.$, kısmi $\left.\eta 2=0.007\right)$.

Ortalama Dist parametresi üzerine görme faktörünün etkisinin gruplar arasında anlamlı fark gösterdiği $\left(\mathrm{F}_{(2,59)}=3.670, \mathrm{p}=0.031\right.$, k1smi $\left.\eta 2=0.111\right)$ ve bu farkın esas olarak antero-posterior yönde yer değiştirmeden kaynaklandıği gözlenmiştir $(\mathrm{p}=0.019)$.

Gruplar arasında ve gruplar içinde Var parametresi açısından istatistiksel olarak anlamlı bir fark olmamasına karş11ık, gruplar arasında antero-posterior $\left(\mathrm{AP}_{\mathrm{var}}\right)$ bileşeni açısından anlamlı fark olduğu bulunmuştur; $\left(\mathrm{F}_{(2,59)}=4.358, \mathrm{p}=0.017\right.$, parsiyel $\eta 2=0.133$ ) (Tablo 3).

Tablo 4. Gözler açık (GA) ve kapalı (GK) durumda futbol (FG), basketbol (BG) ve kontrol (KG) gruplarına ait statik denge ölçümlerinin one-way ANOVA yöntemi ile karşılaştırılması

\begin{tabular}{|c|c|c|c|c|c|c|}
\hline & & $\begin{array}{c}\text { FG } \\
\text { n=17 } \\
\text { Ort (SS) }\end{array}$ & $\begin{array}{c}\text { BG } \\
n=19 \\
\text { Ort (SS) }\end{array}$ & $\begin{array}{c}\text { KG } \\
n=26 \\
\text { Ort (SS) }\end{array}$ & $\mathbf{F}$ & $\mathbf{p}$ \\
\hline \multirow{7}{*}{ GA } & Area & $0.80(0.42)$ & $0.80(0.57)$ & $1.21(1.36)$ & 1.384 & 0.259 \\
\hline & Dist & $74.82(18.69)$ & $87.71(25.81)$ & $94.04(30.02)$ & 2.096 & 0.132 \\
\hline & $\mathrm{ML}_{\text {dist }}$ & $57.49(18.39)$ & $65.18(25.01)$ & $71.18(24.39)$ & 1.308 & 0.278 \\
\hline & $\mathrm{AP}_{\text {dist }}$ & $34.61(8.97)$ & $40.90(11.72)$ & $43.58(17.24)$ & 2.126 & 0.128 \\
\hline & Var & $0.031(0.007)$ & $0.035(0.011)$ & $0.037(0.012)$ & 1.684 & 0.194 \\
\hline & $\mathrm{ML}_{\mathrm{var}}$ & $0.051(0.02)$ & $0.060(0.02)$ & $0.060(0.02)$ & 1.233 & 0.299 \\
\hline & $\mathrm{AP}_{\mathrm{var}}$ & $0.030(0.01)$ & $0.035(0.01)$ & $0.037(0.01)$ & 2.042 & 0.139 \\
\hline \multirow{7}{*}{ GK } & Area & $1.07(0.75)$ & $1.16(0.92)$ & $1.30(1.14)$ & 0.302 & 0.741 \\
\hline & Dist & $77.92(17.95)$ & $91.37(19.46)$ & $94.83(24.94)$ & 5.027 & 0.010* \\
\hline & $\mathrm{ML}_{\text {dist }}$ & $60.61(16.75)$ & $72.02(18.03)$ & $71.01(24.41)$ & 2.270 & 0.112 \\
\hline & $\mathrm{AP}_{\text {dist }}$ & $34.43(7.87)$ & $40.46(9.97)$ & $45.48(10.44)$ & 7.065 & $0.002 *$ \\
\hline & Var & $0.029(0.008)$ & $0.034(0.008)$ & $0.037(0.01)$ & 4.061 & $0.022 *$ \\
\hline & $\mathrm{ML}_{\mathrm{var}}$ & $0.049(0.01)$ & $0.055(0.01)$ & $0.060(0.02)$ & 2.163 & 0.124 \\
\hline & $\mathrm{AP}_{\mathrm{var}}$ & $0.030(0.01)$ & $0.035(0.01)$ & $0.039(0.01)$ & 7.522 & 0.001* \\
\hline
\end{tabular}

Ort.= ortalama; $\mathrm{SS}=$ Standart Sapma; $\mathrm{ML}=$ medio-lateral; $\mathrm{AP}=$ antero-posterior; ${ }^{*} \mathrm{p}<0.05$

Gruplar arasında görme duyusu engellendiğinde (GK) salınım mesafesinde (Dist) istatistiksel olarak anlamlı fark saptanmıştır $\left(\mathrm{F}_{(2,59)}=5.027, \mathrm{p}=0.010\right.$, k1smi $\left.\eta 2=0.146\right)$ (Tablo 4). Post hoc analizinde bu farkın futbol grubu ile kontrol grubu arasında olduğu gözlenmiştir ( $p=0.008)$.

GK durumunda salınım hızı bakımından gruplar arasında istatistiksel olarak anlamlı bir fark saptanmıştır $\left(\mathrm{F}_{(2,59)}=4.061, \mathrm{p}=0.022\right.$, kısmi $\left.\eta 2=0.121\right)$ (Tablo 4). Post hoc analizinde Var, futbol grubunda kontrol grubuna göre istatistiksel olarak anlamlı derecede daha düşük bulunmuştur $(\mathrm{p}=0.018)$.

GK durumunda $A P_{\text {Dist }}$ parametresinde $\left(\mathrm{F}_{(2,59)}=7.065, \mathrm{p}=0.002\right.$, k1smi $\left.\eta 2=0.196\right)$ ve $\mathrm{AP}_{\mathrm{Var}}$ parametresinde $\left(\mathrm{F}_{(2,59)}=7.522, \mathrm{p}=0.001\right.$, k1smi $\left.\eta 2=0.206\right)$ gruplar arasinda istatistiksel olarak anlamlı bir fark saptanmıştır(Tablo 4). Her iki parametre için saptanan anlamlı farkın post hoc analizde futbol ile kontrol grubu arasındaki farktan kaynaklandığı gözlenmiştir (sırasıyla $\mathrm{p}=0.001$ ve $\mathrm{p}=0.001$ ). 


\section{TARTIŞMA VE SONUÇ}

Genç yetişkin erkek gönüllülerde yaptığımız çalışmada spor eğitiminin statik denge parametrelerini olumlu etkilediği ve bu durumun özellikle görme duyusu ortadan kaldırıldığında belirgin olarak ortaya çıktığı gözlenmiştir. Spor eğitimi alan gruplar birlikte değerlendirildiğinde gözler kapalı konumda Dist $(\mathrm{p}=0.023)$ ve $\operatorname{Var}(\mathrm{p}=0.032)$ parametreleri bakımından kontrol grubuna göre anlamlı derecede daha iyi statik dengeye sahip oldukları gösterilmiştir.

Futbol (FG) ve basketbol (BG) sporu ile ilgili eğitim alan gönüllüler ile resim ve müzik eğitimi alan gönüllüler $(\mathrm{KG})$ arasında statik denge parametreleri karşılaştırıldığında, Area parametresinin görme faktörü ile $(p=0.007)$, Dist parametresinin ise grup faktörü ile $(p=0.031)$ anlamlı fark gösterdiği saptanmıştır. Salınım mesafesi verisi vektöriyel bileşenlerine göre değerlendirildiğinde, özellikle antero-posterior yöndeki (APdist) yer değişimin anlamlı olduğu ( $p=0.019$ ) gözlenmiştir. Salınım hızı parametresinde anlamlı fark gözlenmezken, vektöriyel bileşenlerine bakıldığında antero-posterior yöndeki salınım hızı bileşeninin (APvar) grup faktörü ile anlamlı fark gösterdiği saptanmıştır ( $\mathrm{p}=0.017)$.

Gözler kapalı yapılan ölçümlerde Dist ve Var parametrelerinde gruplar arasında anlamlı fark olduğu saptanmıştır. Buna göre futbol grubunda kontrol grubuna göre toplam salınım mesafesinin (Dist) ve Var parametresinin ol anlamlı fark gösterdiğigözlenmiştir (sırasıyla $\mathrm{p}=0.008$ ve $\mathrm{p}=0.018$ ). Vektöriyel bileşenler olarak bakıldığında hem Dist hem de Var için antero-posterior yöndeki (APdist ve APvar) değişimin anlamlı olduğu bulunmuştur ( $\mathrm{p}=0.001$ ).

Liang, Hiley ve Kanosue (2019) kolej öğrencileri arasında en az 8 yıldır futbol ve beyzbol spor eğitimi alan öğrenciler ile hiçbir spor dalı deneyimi olmayan bir öğrenci grubu üzerinde statik denge performansını değerlendirmişlerdir. Bu çalışmada salınım alanının görme (göz açık-göz kapal1), postür (iki ayak, tek ayak ve tek ayak kararsız zemin) ve deneyim durumundan etkilendiği gösterilmiş ve gruplar arasında gözü kapalı durumda futbolcuların anlamlı derecede daha küçük salınım alanı değerine sahip oldukları öne sürülmüştür. Bir temas sporu olarak futbol eğitiminin göz kapalı durumda sadece tek ayak ve kararsız zeminde tek ayak ölçümlerinde diğer gruplardan anlamlı derecede daha az postürel salınım gösterdiklerini bildirmişlerdir. Aynı şekilde BM hızının da göz kapalı durumda göz açık duruma göre tek ayak üzerinde ve kararsız zeminde daha fazla arttığını ve bu parametrenin futbolcularda en iyi olduğunu öne sürmüşlerdir. Bu çalışmada beyzbol sporcuları ile deneyimsiz öğrencilerin statik denge performanslarının hem salınım alanı hem de BM hızı bakımından benzer olduğu ifade edilmiştir.

Düzenli futbol antrenmanı yapan erkek kolej futbolcuları ile kısıtlı fiziksel aktivite yapan erkek kontrol grubunun statik denge performansının, görme (göz açık ve göz kapalı) ve postürel (normal iki ayak duruş ve tandem iki ayak duruş) değişkenlik ile değerlendirildiği bir çalışmada, tüm statik denge parametreleri bakımından futbolcuların sporcu olmayan gruba göre daha üstün olduğu gösterilmiştir (Thompson, Badache, Cale, Behera ve Zhang, 2017). Bu çalışmaları destekler şekilde çalışmamızın sonucunda statik denge parametreleri arasında grup faktörü ve 
görme faktörü bakımından anlamlı fark olup, futbol grubu basketbol grubu ve kontrol grubuna göre üstün değerlere sahip bulunmuştur.

Marchetti'nin basketbol sporu yapan erkek kolej öğrencileri ve sporcu olmayan kontrol grubu erkekler arasında statik denge performanslarının değerlendirildiği çalışmasında, BM yer değiştirme hızının medio-lateral yönde basketbolcularda anlamlı derecede düşük olduğu gösterilmiştir (Marchetti, Hartigan ve Duarte, 2012). Sporun postürel kontrolü olumlu etkilediği bilinmekle beraber, birçok çalışmada basketbolcuların diğer sporlar ile ilgilenen atletlere göre daha kötü statik denge performansına sahip oldukları bilinmektedir (Bressel vd., 2007; Matsuda, Demura ve Uchiyama, 2008). Buradaki temel sorun, ölçüm yapılan grupların antrenman programlarının ne ölçüde denge gelişimine yönelik antrenman programları içerdiklerinin bilinmemesidir. Nitekim genç yetişkin kadın basketbolcularda yapılan bir çalşsmada 8 hafta süreyle denge ve pliyometrik antrenman eklenen sporcuların denge ve çeviklik bakımından anlamlı derecede daha iyi performans gösterdikleri gösterilmiştir (Bouteraa vd., 2020). Genç yetişkin yaş grubu basketbolcularda denge antrenmanlarının akut yaralanmaları önlemek bakımından da önemli olduğu vurgulanmaktadır (Emery vd., 2007). Genç yetişkin erkek futbolcularda sadece futbol antrenmanının statik denge performansı üzerine olumlu etkisinin olmadığı ancak futbol antrenmanı sonrası 12 haftalık denge antrenmanının statik denge performansında anlamlı gelişim sağladığı öne sürülmüştür (Gioftsidou vd., 2006). Bu açıdan bakıldığında aynı sporu yapan genç yetişkin bireylere denge gelişimine yönelik çalışma programı uygulandığında daha iyi statik denge performansına sahip olabildikleri söylenebilir.

Yapılan sporun statik denge bakımından fark yarattığı konusu üzerinden bakıldı̆̆ında, özellikle kararlı olmayan bir zeminde ve topun ayak ile kontrolüne dayanan futbolda hem ayak bileği hem de kalça eklemi ile ilişkili proprioseptif duyunun daha iyi geliştiği öne sürülebilir. Özellikle sert zeminde ayakta sabit durmak gerektiğinde ortaya çıkan hafif vücut salınımında ayak bileği propriosepsiyonu statik dengede önemli rol oynarken, dengenin daha fazla bozulduğu durumlarda kalça propriosepsiyonu önem kazanır (Ricotti, 2011). Futbola özgü antrenman ve sportif özelliklerin ayak bileği propriosepsiyonunun daha iyi gelişmesini sağlayarak statik dengenin daha iyi olmasını sağladığı düşünülebilir. Ancak bu durumun sert zeminde olabileceğini, kararsız zeminde ise merkezi sinir sisteminin proprioseptif kaynaklarının ağırlığını değiş̧irmeye zorlayan bir durumun ortaya çıktı̆̆ı ileri sürülmektedir (Kiers, Brumagne, Van Dieen, van der Wees ve Vanhees, 2012). Stambolieva kayak ve kanocular ile spor yapmayan kontrol grubu üzerinde yaptığı çalışmada ise, sporcuların kararlı zeminde gözleri açıkken kontrol grubuna göre daha kötü statik denge performansı göstermelerine karşılık, gözleri kapalıyken bu farkın ortadan kalktığını bildirmektedir. İlginç bir şekilde kararsız zeminde gözler kapalı durumda sporcular aleyhine anlamlı fark ortaya çıkmaktadır ve sporcuların görme duyusuna daha fazla bağımlı oldukları bildirilmektedir (Stambolieva vd., 2012). Denge antrenmanları hem sportif performans hem de sakatlıkların önlenmesi bakımından önemli olmakla birlikte, yapılan sporun özelliklerinin hem statik denge performansı gelişimi hem de duyuların ağırlıklandırılmasında daha belirleyici olduğu görülmektedir. 
$\mathrm{Bu}$ açıdan bakıldığında futbol antrenman programının basketbol antrenman programından daha iyi postürel kontrol gelişimi sağladığı öne sürülebilir. Bir başka ifade ile farklı spor dallarının farklı duyusal girdilere ihtiyaç duymasına bağlı olarak değişen durumlara adaptasyon ve yeniden ağırlıklandırma konusunda farklılık gösterdikleri ortaya çıkmaktadır. Futbolun statik denge performansının gelişimine daha olumlu etki yapan bir spor olduğunu ve adölesan erkek futbolcuların görme duyusu ortadan kaldırıldığında proprioseptif duyuyu daha etkili bir şekilde kullanarak daha üstün statik denge performansı gösterdiklerini söyleyebiliriz.

Bu kesitsel çalışmada grupların demografik verileri arasında (boy ve ağırlık ortalaması) anlamlı fark olması kısıtlılık olarak görülmektedir. Özellikle boyun statik dengeyi etkileyebileceği bilinmektedir (Alonso vd., 2015). Bu bakımdan diğer gruplara göre daha uzun boy ortalamasına sahip olan basketbol grubu için olumsuz bir faktör olduğunu kabul etmek gerekir. Ancak istatistik sırasında grupların kendi içinde de değerlendirme yapıldığından, yorum için yeterli veriyi aldığımızı düşünüyoruz.

Hem sporun gereklilikleri hem de antrenman programlarının içerdiği antrenman teknikleri bakımından genç yetişkin yaş grubu erkeklerde futbol eğitiminin spor yapmayanlara ve basketbol eğitimi alanlara göre görme duyusuna daha az ihtiyaç duyacak şekilde, başka bir deyiş ile duyuları daha iyi yeniden ağırlıklandırma yoluyla daha üstün statik denge gelişimi sağladığını öne sürebiliriz.

\section{ÖNERILLER}

Bu çalışmada genç yetişkin erkeklerde sporun postürel kontrol ve denge gelişimi üzerinde etkili olduğu ve özellikle futbol gibi kararsız zeminde yapılan bir spor ile ilgili antrenman yöntemlerinin postürel kontrolde etkili duyusal girdileri daha iyi yeniden ağırlıklandırabilmesinden yola çıkılarak, basketbol gibi kararlı zeminde yapılan sporların yol açabileceği sakatlıkların önlenmesi bakımından, duyusal yeniden ağırlıklandırabilmeyi geliştiren antrenman yöntemlerine daha fazla önem verilmelidir.

Çıkar Çatışması: Çalışma kapsamında araştırmacılar arasında herhangi bir kişisel ve finansal çıkar çatışması bulunmamaktadır.

Araştırmacıların Katkı Oranı Beyanı: Araştırma Dizaynı- HK; TV, İstatistik analiz- SÖ; TV, Makalenin hazırlanmas1- HK; SÖ; TV, Verilerin Toplanmas1- HK: tarafindan gerçekleştirilmiştir.

\section{Etik Kurul İzni ile ilgili Bilgiler}

Kurul Adı: Manisa Celal Bayar Üniversitesi Tıp Fakültesi Girişimsel Olmayan Klinik Araştırmalar Etik Kurulu

Tarih: 13.12.2012

Sayı/Karar No: 298 


\section{KAYNAKLAR}

Alonso, A. C., Mochizuki, L., Silva Luna, N. M., Ayama, S., Canonica, A. C. \& Greve, J. M. (2015). Relation between the sensory and anthropometric variables in the quiet standing postural control: Is the inverted pendulum important for the static balance control? BioMed Research International, 2015, 1-5. https://doi.org/10.1155/2015/985312.

Behm, D. G. \& Anderson, K. G. (2006). The role of instability with resistance training. Journal of Strength and Conditioning Research, 20(3), 716-722. https://doi.org/10.1519/R18475.1.

Bouteraa, I., Negra, Y., Shephard, R. J. \& Chelly, M. S. (2020). Effects of combined balance and plyometric training on athletic performance in female basketball players. The Journal of Strength \& Conditioning Research, 34(7), 1967-1973. https://doi.org/10.1519/JSC.0000000000002546.

Bressel, E., Yonker, J. C., Kras, J. \& Heath, E. M. (2007). Comparison of static and dynamic balance in female collegiate soccer, basketball, and gymnastics athletes. Journal of Athletic Training, 42(1), 42-46. https://pubmed.ncbi.nlm.nih.gov/17597942/

Chiba, R., Takakusaki, K., Ota, J., Yozu, A. \& Haga, N. (2016). Human upright posture control models based on multisensory inputs; in fast and slow dynamics. Neuroscience Research, 104, 96-104. https://doi.org/10.1016/j.neures.2015.12.002.

Cumberworth, V., Patel, N., Rogers, W. \& Kenyon, G. (2007). The maturation of balance in children. The Journal of Laryngology \& Otology, 121(5), 449-454. https://doi.org/10.1017/S0022215106004051.

Emery, C. A., Cassidy, J. D., Klassen, T. P., Rosychuk, R. J. \& Rowe, B. H. (2005). Effectiveness of a home-based balance-training program in reducing sports-related injuries among healthy adolescents: a cluster randomized controlled trial. Canadian Medical Association Journal, 172(6), 749-754. https://doi.org/ 10.1503/cmaj.1040805.

Emery, C. A., Rose, M. S., McAllister, J. R. \& Meeuwisse, W. H. (2007). A prevention strategy to reduce the incidence of injury in high school basketball: a cluster randomized controlled trial. Clinical Journal of Sport Medicine, 17(1), 17-24. https://doi.org/10.1097/JSM.0b013e31802e9c05.

Fetsch, C. R., Turner, A. H., DeAngelis, G. C. \& Angelaki, D. E. (2009). Dynamic reweighting of visual and vestibular cues during self-motion perception. Journal of Neuroscience, 29(49), 15601-15612. https://doi.org/10.1523/JNEUROSCI.2574-09.2009.

Gerbino, P. G., Griffin, E. D. \& Zurakowski, D. (2007). Comparison of standing balance between female collegiate dancers and soccer players. Gait \& Posture, 26(4), 501-507. https://doi.org/10.1016/j.gaitpost.2006.11.205.

Gioftsidou, A., Malliou, P., Pafis, G., Beneka, A., Godolias, G. \& Maganaris, C. N. (2006). The effects of soccer training and timing of balance training on balance ability. European Journal of Applied Physiology, 96(6), 659-664. https://doi.org/10.1007/s00421-0050123-3. 
Hellström, J. (2009). Competitive elite golf: A review of the relationships between playing results, technique and physique Sports Medicine, 39(9), 723-741. https://doi.org/10.2165/11315200-000000000-00000.

Hirabayashi, S.I. \& Iwasaki, Y. (1995). Developmental perspective of sensory organization on postural control. Brain and Development, 17(2), 111-113. https://doi.org/ 10.1016/0387-7604(95)00009-z.

Horak, F. B. \& Macpherson, J. M. (2010). Postural orientation and equilibrium. Comprehensive Physiology, 255-292. https://doi.org/10.1002/cphy.cp120107.

Hrysomallis, C. (2011). Balance ability and athletic performance. Sports Medicine, 41(3), 221232. https://doi.org/ 10.2165/11538560-000000000-00000.

Kiers, H., Brumagne, S., Van Dieen, J., van der Wees, P. \& Vanhees, L. (2012). Ankle proprioception is not targeted by exercises on an unstable surface. European Journal of Applied Physiology, 112(4), 1577-1585. https://doi.org/10.1007/s00421-011-2124-8.

Lamoth, C. J., van Lummel, R. C. \& Beek, P. J. (2009). Athletic skill level is reflected in body sway: a test case for accelometry in combination with stochastic dynamics. Gait \& Posture, 29(4), 546-551. https://doi.org/10.1016/j.gaitpost.2008.12.006.

Liang, Y., Hiley, M. \& Kanosue, K. (2019). The effect of contact sport expertise on postural control. PloS One, 14(2), e0212334. https://doi.org/10.1371/journal.pone.0212334.

Marchetti, P. H., Hartigan, E. H. \& Duarte, M. (2012). Comparison of the postural control performance of collegiate basketball players and nonathletes. Athletic Training and Sports Health Care, 4(6), 251-256. https://doi.org/10.3928/19425864-20121005-01.

Matsuda, S., Demura, S. \& Uchiyama, M. (2008). Centre of pressure sway characteristics during static one-legged stance of athletes from different sports. Journal of Sports Sciences, 26(7), 775-779. https://doi.org/10.1080/02640410701824099.

Maurer, C., Mergner, T. \& Peterka, R. J. (2005). Multisensory control of human upright stance. Experimental Brain Research, 171(2), 231-250. https://doi.org/10.1007/s00221-0050256-y.

Nolan, L., Grigorenko, A. \& Thorstensson, A. (2005). Balance control: sex and age differences in 9-to 16-year-olds. Developmental Medicine and Child Neurology, 47(7), 449-454. https://doi.org/10.1017/s0012162205000873.

Paillard, T. (2014). Sport-specific balance develops specific postural skills. Sports Medicine, 44(7), 1019-1020. https://doi.org/10.1007/s40279-014-0174-x.

Paillard, T. \& Noé, F. (2006). Effect of expertise and visual contribution on postural control in soccer. Scandinavian Journal of Medicine \& Science in Sports, 16(5), 345-348. https://doi.org/10.1111/j.1600-0838.2005.00502.x.

Peterson, M. L., Christou, E. \& Rosengren, K. S. (2006). Children achieve adult-like sensory integration during stance at 12-years-old. Gait \& Posture, 23(4), 455-463. https://doi.org/10.1016/j.gaitpost.2005.05.003. 
Ricotti, L. (2011). Static and dynamic balance in young athletes. Journal of Human Sport and Exercise, 6(4), 616-628. https://doi.org/10.4100/jhse.2011.64.05.

Sparto, P. J., Redfern, M. S., Jasko, J. G., Casselbrant, M. L., Mandel, E. M. \& Furman, J. M. (2006). The influence of dynamic visual cues for postural control in children aged 712 years. Experimental Brain Research, 168(4), 505-516. https://doi.org/10.1007/s00221-005-0109-8.

Stambolieva, K., Diafas, V., Bachev, V., Christova, L. \& Gatev, P. (2012). Postural stability of canoeing and kayaking young male athletes during quiet stance. European Journal of Applied Physiology, 112(5), 1807-1815. https://doi.org/10.1007/s00421-011-2151-5.

Steindl, R., Kunz, K., Schrott-Fischer, A. \& Scholtz, A. (2006). Effect of age and sex on maturation of sensory systems and balance control. Developmental Medicine and Child Neurology, 48(6), 477-482. https://doi.org/10.1017/S0012162206001022.

Thompson, L. A., Badache, M., Cale, S., Behera, L. \& Zhang, N. (2017). Balance performance as observed by center-of-pressure parameter characteristics in male soccer athletes and non-athletes. Sports, 5(4), 1-9. https://doi.org/10.3390/sports5040086.

Vuillerme, N., Danion, F., Marin, L., Boyadjian, A., Prieur, J., Weise, I. \& Nougier, V. (2001). The effect of expertise in gymnastics on postural control. Neuroscience Letters, 303(2), 83-86. https://doi.org/ 10.1016/s0304-3940(01)01722-0.

Weineck, J. (2004). Optimales training: Leistungsphysiologische trainingslehre unter besonderer berücksichtigung des kinder-und jugendtrainings: Spitta Verlag GmbH \& Co. KG.

Winter, D. A. (1995). Human balance and posture control during standing and walking. Gait \& Posture, 3(4), 193-214. https://doi.org/10.1016/0966-6362(96)82849-9.

Young, L. R., Oman, C. M., Watt, D. G. D., Money, K. E., Lichtenberg, B. K., Kenyon, R. V. \& Arrott, A. P. (1986). M.I.T./Canadian vestibular experiments on the Spacelab-1 mission: 1. Sensory adaptation to weightlessness and readaptation to one-g: an overview. Experimental Brain Research, 64(2), 291-298. https://doi.org/10.1007/BF00237746.

Zech, A., Hübscher, M., Vogt, L., Banzer, W., Hänsel, F. \& Pfeifer, K. (2010). Balance training for neuromuscular control and performance enhancement: a systematic review. Journal of Athletic Training, 45(4), 392-403. https://doi.org/10.4085/1062-6050-45.4.392.

Zemková, E. (2014). Author's reply to Paillard T: "Sport-specific balance develops specific postural skills". Sports Medicine, 44(7), 1021-1023. https://doi.org/10.1007/s40279014-0175-9.

Bu eser Creative Commons Atıf-Gayri Ticari 4.0 Uluslararası Lisansı ile lisanslanmıştır. 